JOURNAL OF SECURITY AND SUSTAINABILITY ISSUES ISSN 2029-7017 print/ISSN 2029-7025 online 2020 March Volume 9 Number 3 https://doi.org/10.9770/jssi.2020.9.3(5)

\title{
SMART CITIES: IMPACT OF RENEWABLE ENERGY CONSUMPTION, INFORMATION AND COMMUNICATION TECHNOLOGIES AND E-GOVERNANCE ON CO2 EMISSION
}

\author{
Witthaya Mekhum \\ Suan Sunandha Rajabhat University, Bangkok, Thailand \\ E-mail:witthaya.me@ssru.ac.th
}

Received 13 March 2019; accepted 23 November 2019; 30 March 2020

\begin{abstract}
Renewable energy is not only cost effective but also plays vital role in decreasing the pollution. Most of the developing countries struggle with the energy supply for the cities. The introduction of renewable energy resources will not only meet the increased city demand of energy but also helps in making the smart city. Information and communication technologies help in efficient communication and work using different soft wares. The better the Information and communication technologies services in the country the better will be the chance of generating the smart cities in Asia. Emission of $\mathrm{CO}_{2}$ contributes to the pollution and thus, the global warming. If the government, make better policies and communicate it with e-governance with the people of the country then there will be the chances of making the smart cities in the Asia. The aim of this study was to assess the impact of three dependent variables including state legitimacy, democracy and public services on the independent variables on the quality of the education. The data was collected from ten different Asian countries including are incudes Pakistan, India, China, Bangladesh, Nepal, Afghanistan, Iran, Turkey, Maldives, Indonesia, Saudi Arab, Kazakhstan, Syria, Qatar and Iraq. The timeline of the study is 26 years from 2019 and the data was collected from The Economic Form, The World Bank reports as well as the Transparency International. The analysis was performed by using IBM-SPSS and various statistical tests were applied including LLC, cointegration test diagnostic checks, correlation matrix and PCSE estimation test and sysGMM. The results of our study showed positive association of dependent variables on the formation of smart cities in Asia. The results of our study have social, political and economic implications.
\end{abstract}

Keywords: Renewable Energy Consumption; Information and Communication Technologies; E-Governance, Co2 Emission, Asia

Reference to this paper should be made as follows: Mekhum, W. 2020. Smart cities: impact of renewable energy consumption, information and communication technologies and e-governance on CO2 emission. Journal of Security and Sustainability Issues, 9(3), 785-795. https://doi.org/10.9770/jssi.2020.9.3(5)

JEL Classification: $\mathrm{O} 3$

\section{Introduction}

A greenhouse gas is identified as any such compound that is enough able to absorb and emit infrared radiation, therefore permitting less heat to get escaped back to space and then making a trap of it in some lower environment. Ozon, Nitrous oxide, methane, carbon dioxide (CO2) and water vapors are the major greenhouse gases present in the environment of Earth (Adapa, 2018). The emissions of CO2 is done through burning the fossil fuels for different uses (Agbali, Trillo, Ibrahim, Arayici, \& Fernando, 2019; Haseeb, Wattanapongphasuk, \& Jermsittiparsert, 2019). In accordance with Alonso-Gonzalez, Chacon, and Peris-Ortiz (2018), the electricity is mainly produced through burning fossil fuels, that mainly come through natural gas and coal. The emissions of greenhouse through industry mainly come through burning of fossil fuels for the purpose to acquire energy. It is also used for various other processes of industry (see figure 1). 


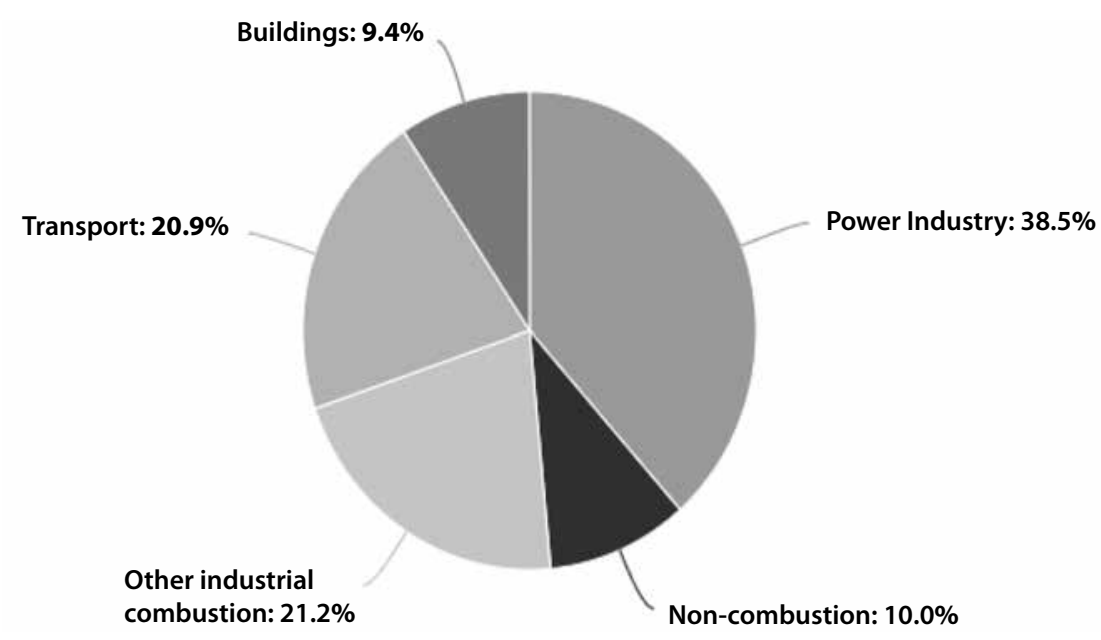

Figure 1. CO2 Emissions by Sector

For instance, it is used for transportation purposes. Fossil fuels are burnt for planes, trains, ships, trucks and cars. Different chemical reactions are considered important to develop products from raw items, like non-energy usage of fuels, use of dolomite and limestone. Greenhouse gas emission through homes and businesses arise mainly because of fossil fuels that is burnt for the purpose to get heat. Excluded burning of biomass of shortcycle (like burning of agricultural waste), burning of biomass of larger scale (like forest fires) and removals/ emissions of carbon of land-usage are also the causes why CO2 is emitted. In accordance with (Andrés, 2019), in year 2016, there were 35,753,305,000 tons of emission of CO2. The emissions of CO2 got incremented by around 0.34 percent over the past year, depicting an increment in year 2015 of around 122,227,000 tons within Asian countries (Balogun et al., 2019). In figure 1, the trends of CO2 emission are provided.

In an attempt to overcome the climate change and energy crisis, the government present around the world and particularly within Asia are targeting on renewable energy resource. Natural resources are used for deriving renewable energy like hydro, geothermal, wind and solar energy, and some types of biomass that get replenished at much faster rate as compared to their consumption. The renewable sources of energy can provide developing countries of Asia an opportunity to accept electrification of rural regions and low pathway of carbon through off-grid solutions of renewable energy (Bhatt \& Jani, 2019). Information and Communication technology mainly refers to the technology that is mainly used for the purpose to handle network-based control, transmission and processing system, broadcast media, telecommunication and intelligent building management systems. However, ICT is often identified as the synonym for IT, but still it has broader scope. Currently, within Asian countries, ICT has been used mainly to define the convergence of various technologies and using the lines of transmission carrying a diverse type of data and different formats and types of communication (Efthymiopoulos, 2016). In accordance with Gassmann, Böhm, and Palmié (2019), governance quality can be helpful for long-term development. However, there is still lesser literature on governance directions to emissions of $\mathrm{CO} 2$ within Asian countries. In the past, no research has been done to analyse the influence of renewable energy consumption, information communication and technology and e-governance on Co 2 emissions of Asian countries. Therefore, the current research has been done to fill the gap present in literature. The research is dependent over given key objectives:

- To analyze the influence of renewable energy consumption on Co2 emissions in Asian countries

- To study the impact of information communication and technology on Co2 emission in Asian countries

- To analyze the influence of e-governance on Co2 emission in Asian countries

The outcomes of this study are beneficial for authorities of government and also for the reduction of Co2 emission in Asian countries. It will help in making the countries to get good and pollution free environment.

The division of this dissertation has been done into five major chapters. The first one is Introduction, then Literature Survey, Methodology, Analysis, Findings and Conclusion. 


\section{Literature Review}

\section{Impact of Energy Consumption on Co2 emission}

In accordance with Gupta, Chauhan, and Jaiswal (2019), there are difference factors that affect the alterations in the energy level linked with $\mathrm{Co} 2$ emissions. It has been identified that $\mathrm{CO} 2$ emissions within the industrial region is now a decrementing trend because of the improved fuel switching and energy efficiency. However, the intensity of energy varied a broader range and had more influence over the emissions of $\mathrm{CO} 2$ as compared to the coefficient of pollution. Some of the important changes that are made in the structure of renewable energy results into emissions of CO2. In the research of Hayat (2016), the intensity of energy and effect of carbon index were negatively linked. Within Iran, a one-way causal link was found in between Co 2 emission and consumption of renewable energy like gas consumption and other petroleum items. However, there was no such proof that consumption of fossil fuels, petroleum products and $\mathrm{CO} 2$ emission resulted into economic development. Within South Africa, there is a positive influence of $\mathrm{Co} 2$ emission over the consumption of energy. Same like this, Khatavkar, Naik, and Kadam (2017) also depicted a positive link in between emissions of CO2 and energy consumption in eight of the Asian countries. Despite the fact that the usage of CO2 emissions per capita and within developing countries, the energy efficiency is lower as compared to that of developed ones. It is because of the reason that energy per unit is higher as compared to that in developed countries. In accordance with (Kim, 2018), in the long race, there is a positive influence of energy consumption over emissions of CO2. China is most leading one in the field of renewable energy in the entire region. Out of the entire consumption of total energy of 94,799 petajoule, the attainment of 11,282 petajoule is done through renewable energy. This implies that around 11 percent of the requirements of energy are fulfilled through renewable resources of energy. In accordance with Kim (2019), different other countries like Indonesia, Pakistan, Philippines and Sri Lanka are also fulfilling the requirements of energy through renewable energy.

H1: There is a significant impact of energy consumption on $\mathrm{CO} 2$ emission in Asian countries.

\section{Impact of Communication and Technologies on $\mathrm{CO} 2$ emission}

To classify and consolidate different applications of ICT with Green House Gases benefits in Asian countries, a tiered system is suggested (T. V. Kumar, 2017). In accordance with A. Kumar (2017) tier 1 does the differentiation between the different categories (dependent on the region in which deployment of ICT is done). These areas can be knowledge and behavior, energy supply systems, production, commerce and services, communication and transportation and smart building. The applications of ICT involve ICT services, ICT components and ICT products. This permits structural analysis that can occur within the society, like transition through economy of products to some service economy (Kumar, 2020). For instance, a company of car can do introduction of new vehicle device that assists drives to adopt such styles of driving that decreases emissions of $\mathrm{CO} 2$ and does collection of data on behavioral alterations and acquire reduction in $\mathrm{CO} 2$ emission. The reduction in $\mathrm{CO} 2$ emission caused by the new system can be involved in category of transportation (Yigitcanlar et al., 2018). As different other system can also result into changes in the driving conduct and emission reduction of $\mathrm{CO} 2$, like intelligent systems of transport that are seen dependent over the centralized system for traffic management. The insight acquired through analyzing the influence of in-vehicle systems (referring to emissions done per kilometer driven) can help in defining appropriate parameters for integrating and assessing the intelligent solutions of transport systems (Mboup \& Oyelaran-Oyeyinka, 2019). Different applications of ICT affect CO2 emission with the help of various channels, and it influence various variables. For instance an application of ICT that make improvement in building strategies can decrease the materials' volume used through the industry of building or the composition of this (Yigitcanlar, 2016). On the other hand, deploying smarter controls within buildings can make a decrement in the operational hours of some equipment and the linked emissions (Menkhoff, Kan, Evers, \& Chay, 2017; Vlasov, Grigoriev, Krivoshein, Shakhnov, Filin, Migalin, 2019; Sarma, Karnitis, Zuters, Karnitis, 2019; Vlasov, Shakhnov, Filin, Krivoshein, 2019).

H2: There is a significant impact of Information Communication and Technology on Co2 emission in Asian countries 


\section{Impact of E-governance on Co2 Emission}

Different approaches of governance can impose both indirect and direct influences over the extent of emissions of $\mathrm{CO} 2$. One such direction of governance is the law rule. Where the law rule exists, a decrement can be made in the influences of failure of market (Praharaj \& Han, 2019). Particularly, Pozdniakova (2017) identified that institutions' quality can support more cooperation among the players of market. Ryser (2016) has stated that good institutions are the ones that protect and secure various property rights. When business get more entitlement for legal protection with the help of registration, property rights generate more of the incentives for making use of resources for the purpose of efficient development. Sánchez-Corcuera et al. (2019) has identified that institution can be weak because of lesser number of rules. Within Asia, the useful rules are enforced poorly, and it then becomes counterproductive in case when there are higher costs of enforcement and monitoring. Within Asia, the law rules become most important to comply with when referring to $\mathrm{CO} 2$ emissions. Where there are rules, $\mathrm{CO} 2$ control processes are imposed easily, and organizations do not hesitate to comply with rules. The other aspect for e-governance mainly linked with the law rule that can be significant in terms of emissions of $\mathrm{CO} 2$ within Asian countries is the absence of some legal procedure for enforcing the contracts of business. In accordance with Sharifi (2019), if there are no such plans of enforcement, then organizations may not comply with contract provision. Thus, it can be hypothesized that contracts' enforcement can assist to cause more compliance-oriented organizations and such organizations that mainly comply with contracts of business tend to comply with the national policies of environment. The quality of regulatory can also influence the environmental results. In accordance with Smith, Pathak, and Agrawal (2019), heavy entry regulations for organizations in markets is linked with government having less democracy, larger unofficial economies and more corruption. Heavier regulation of activities of organization can manifested in different forms like in the form of superfluous statutes, arbitrary taxation, hidden fees for licenses and permits (Hussain et al., 2019). Asian countries developing clear guidelines in accordance with the issuance of taxation, fees charged, and permits can expect organizations to follow regulatory framework in terms of industrial management and production of industry through byproducts. North Asia has argued countries present in the third world are mainly poor due to different constraints on institutions that does not motivate the activity of production (Tomor, Meijer, Michels, \& Geertman, 2019). Along with it, Sureshchandra, Bhavsar, and Pitroda (2016) has stated that institution development is the major issue that is faced while doing transition and development of economies at current time. Good governance of activities of market can support the decrement of $\mathrm{CO} 2$ emission.

H3: There is a significant impact of e-governance on $\mathrm{Co} 2$ emission in Asian countries

\section{Methodology}

\section{Data}

The data in the present study was collected from 15 Asian countries to assess the impact of renewable energy consumption, information and communication technologies and E-governance on CO2 Emission. These Asian countries incudes Pakistan, India, China, Bangladesh, Nepal, Afghanistan, Iran, Turkey, Maldives, Indonesia, Saudi Arab, Kazakhstan, Syria, Qatar and Iraq. The data regarding dependent variables are taken from different international forums like Transparency International, The World Bank and The Global Economy. These are very reliable and authentic sources from which data has been collected. The data was collected of 26 years ending at 2019. After collection of data, the measurement units of each of the variables included in this study were determined.

\section{Model Used}

The basic motive behind this study is to investigate and check the impact that renewable energy consumption, information and communication technologies and E-governance on $\mathrm{CO} 2$ emission to make Asia a smart country. First of all, the variables must be classified among dependent, independent and control variables. Different approaches are used to like LLC test, diagnostic checks, correlation matrix and PCSE estimation. The 
units of measurements are also included in the study. The measurement of renewable energy consumption was taken as the percentage of using the solar energy, hydroelectrically energy, geothermal energy, wind energy and energy from the biomass. The measurement for information and communication technology was taken on the basis of the number of different software's that are used in different departments of the country. Also, the internet system like $3 \mathrm{G}, 4 \mathrm{G}$ and $5 \mathrm{G}$ technologies used in the country as well. The third dependent variable was E-Governance on $\mathrm{Co} 2$ Emission and it was measured on the basis of the technologies and policies used to decrease the $\mathrm{CO}_{2}$ emission. Three controls were used in the study to compare the results of our study. First is the GDP and it was measured in terms of the annual domestic growth of the country taken in US dollars. The second control taken was population growth. It is measured in terms of number of the population increase per year of the country. The third control variable was the amount of $\mathrm{CO}_{2}$ in the country. It is measured in the parts per millions. In this study has made a regression equation involving all the above-mentioned variables and is given as:

In the above given equation, SC shows the term ready for smart city, REC shows renewable energy consumption, ICT shows information and communication technologies, EG shows E-governance on CO2 Emission GDP shows population, PG shows literacy rate. PCI shows per capita income and is used to represent error. The series is converted to the to the per capita and the model after the log form can be written as,

\section{Estimation Procedure}

To analyze the collected data, the author has used several techniques and approaches such as LLC test, diagnostic checks, correlation matrix and PCSE estimation test and sys-GMM for various purposes. The details of each of these tests are given below:

\section{LLC unit root}

The first test that is used in this study in order to analyze and scrutinize the collected data is unit root test. This test has been designed in order to find out the order of integration and stationarity of the variables involved in the study. Im Pesaran Shin IPS and Levin Lin Chu LLC are the most basic and important tests that are used for the above-mentioned purpose. The preference to use these tests over the old and conventional tests is based on the fact that they resolve certain issues regarding size and power of the collected data (Levin, Lin, \& Chu, 2002). In addition, these tests provide normal standard distribution unlike of the old tests. In this particular study the author has employed LLC unit root test. Another important point that must be noted here is that LLC provides homogeneous autoregressive process while IPS provides heterogeneous autoregressive process. There are two types of hypotheses that are involved in these tests i.e. null and alternate hypothesis. The null hypothesis is characterized by the presence of unit root resulting in non-stationarity of data while the alternate hypothesis is characterized by the absence of unit root resulting in the stationarity of the collected data. The author has applied the following equation in order to use the LLC unit root test:

Here is the difference that shows for $i^{\text {th }}$ country for the specific time period of $t$.

\section{Diagnostic checks}

For the assessment of the data different diagnostic test are applied that are shown below:

\section{Heteroskedasticity}

If different number of variables are present in the population under study, then this condition is recognized as the heteroskedasticity. The absence of homoscedasticity in any data may be can be quantified by using the variance. This is important to check before applying the regression analysis and ANOVA so that the significance values of these test cannot be invalidated. The heteroskedasticity is when the random and the vector of random variable changes with time. 


\section{Autocorrelation}

Autocorrelation is seen between the two-value including the function of two times and the time lag. For this autocorrelation if Pearson correlation is taken from the real or the complex data

In this equation, E shows the expected value.

\section{Multicollinearity}

Multicollinearity is used in the regression analysis of the data. In multicollinearity the data is assessed for the presence of the variable that can act as the predictor for the other variables. By predicting linearity of that variable other variables can also be assessed.

\section{Correlation Matrix}

The correlation matrix showed the association between the two variables. This can be seen in the scattered plot as the liner line among the two variables. For this analysis two things are compared one is the interval variable and other is the ratio of the variable. In the table the value 1 will be considered as the presence of liner relationship among the variables and the 0 shows the absence of linear relationships of the variables. The number between 1 and 0 showed the strength of the model.

\section{PCSE and Sys-GMM estimation}

The panel corrected standard error is used in the time series and also in the cross-sectional data. Sys-GMM estimation is the statistical approach integrating measured economic data with population-time information to obtain estimates of uncertain economic model parameters. The Sys-GMM model corrects both the hetero and serial correlation where ad the PCSE only corrects the hetero one. In some studies Sys-GMM estimation is preferred over PCSE. These models are used to check the static and dynamic estimation of the data.

\section{Results and Analysis}

In our study a heterogeneous panel data approach is used for the analysis of the regression model.

\section{LLC unit root}

The results of LLC unit roots are given in the table 1. This test was applied in order to investigate the order of integration and to check the stationary properties of the variables. Whereas, in LLC test all variables except our control variables like GDP, PG and $\mathrm{CO}_{2}$ have accepted the null hypothesis this means that majority of acceptance by our dependent variables shows that in level series, unit root exists, and the data is non-stationary. But after applying the log the data became stationary by all the control and dependent variables as shown by the first differentiation series in LLC test.

Table 1. Table of LLC unit root

\begin{tabular}{|c|c|c|}
\hline Constructs & Level & $1^{\text {st }}$ difference \\
\hline REC & -1.239 & $-5.299^{* *}$ \\
ICT & -2.483 & $-6.299^{* * *}$ \\
EG & -1.209 & $-9.395^{* * *}$ \\
GDP & $-8.309^{*}$ & $-10.864^{* * *}$ \\
PG & $-5.395^{*}$ & $-9.395^{* * *}$ \\
CO2 & $-3.984^{*}$ & $-8.338^{* *}$ \\
\hline
\end{tabular}




\section{Diagnostic checks}

To check the presence of heteroskedasticity the tests applied were MW. Breusch-Pagan/Cook-Weisberg in the data. Wooldridge test was used to check the autocorrelation, Pesaran test was used to check the CD dependence and VIF test to check the multicollinearity of the variables in our data. The results of the study showed that the presence of heteroskedasticity in our data as the chi-square value was 4.74 for the MW. Breusch-Pagan test and 3.85 for the Cook-Weisberg test. Autocorrelation was also present in the data as the results of F-statistics showed the value of 5.38. The CD dependence was also present in our data. The test statistics results showed the significant value of 2.833. in our data there was no multicollinearity was present as the mean VIF values after the test came out to be 1.64 . See table 2 .

Table 2. Table of Diagnostic checks

\begin{tabular}{|c|c|c|}
\hline Heteroskedasticity & MW. Breusch-Pagan/Cook-Weisberg & $\chi 2$-value: $4.74 * * / \chi 2$-value: $3.85 *$ \\
\hline Autocorrelation & Wooldridge & F-statistic: $5.38^{*}$ \\
\hline CD dependence & Pesaran & Test statistic: $2.833^{*}$ \\
\hline Multicollinearity & VIF & Mean VIF: 1.64 \\
\hline
\end{tabular}

\section{Correlation Metrix}

To check the correlation matrix the Wooldridge test was applied. The results of the correlation matrix showed that renewable energy consumption is related will all the other dependent variables (information and communication technologies and E-governance on CO2 Emission) and controls (population growth, $\mathrm{CO}_{2}$ and GDP). Whereas, ICT was correlated with the E-governance on $\mathrm{CO} 2$ Emission and controls variables (population growth, $\mathrm{CO}_{2}$ and GDP). And the E-governance on $\mathrm{CO} 2$ Emission was correlated with only the controls. See table 3 .

Table 3. table of Correlation Metrix

\begin{tabular}{|c|c|c|c|c|c|c|}
\hline Variables & REC & ICT & EG & GDP & PG & CO2 \\
\hline REC & 1 & & & & & \\
ICT & .454 & 1 & & & & \\
EG & .354 & .584 & 1 & & & \\
GDP & .474 & .354 & .354 & 1 & & \\
PG & .354 & .463 & .456 & .454 & 1 & \\
CO2 & .355 & .543 & .345 & .455 & .582 & 1 \\
\hline
\end{tabular}

\section{PCSE estimation and Sys-GMM estimation}

The results of our study showed that our use to renewable resources have significant impact on the independent variable contributing $19.4 \%$ by PCSE estimation and 18.3 in sys-GMM estimation. The information and communication technologies was significant in PCSE model give rise up to $18.3 \%$ for making Asian countries the smart cities whereas, Sys-GMM estimation showed no significance. The E-governance on CO2 Emission (EG) contributes in the smart city by $18.3 \%$ according to the PCSE estimation and $16.9 \%$ in sym-GMM estimation. GDP of the country showed no correlation in both models whereas, population growth showed $20.3 \%$ and $19.4 \%$ by PCSE and sys-GMM estimation respectively. Overall the impact of our three dependent variables is $59.3 \%$ increase on the independent variables. See table 4. 
Table 4. Results from PCSE estimation and Sys-GMM estimation

\begin{tabular}{|c|c|c|}
\hline Dependent Variable $=\mathrm{CO} 2$ & PCSE estimation & Sys-GMM estimation \\
\hline REC & $\begin{array}{c}0.194 * * \\
(0.538)\end{array}$ & $\begin{array}{c}0.183^{* *} \\
(0.493)\end{array}$ \\
\hline ICT & $\begin{array}{r}0.183^{* *} \\
(0.548)\end{array}$ & $\begin{array}{c}0.173 \\
(0.593)\end{array}$ \\
\hline EG & $\begin{array}{c}0.183 * * \\
(0.719)\end{array}$ & $\begin{array}{c}0.169 * * \\
(0.582)\end{array}$ \\
\hline GDP & $\begin{array}{l}0.101 \\
(0.931)\end{array}$ & $\begin{array}{c}0.091 \\
(0.840)\end{array}$ \\
\hline PG & $\begin{array}{r}0.203 * * \\
(0.393)\end{array}$ & $\begin{array}{c}0.194 * * \\
(0.503)\end{array}$ \\
\hline Constant & $\begin{array}{c}3.284 * * \\
(1.020)\end{array}$ & $\begin{array}{c}2.848 * * \\
(1.002)\end{array}$ \\
\hline$R^{2}$ & $\begin{array}{c}0.593 * * \\
(0.895)\end{array}$ & - \\
\hline No. of Observations & 252 & - \\
\hline No. of Instruments & - & 250 \\
\hline No. of Observations & - & 250 \\
\hline Arellano-Bond test for $A R(1)(\operatorname{Pr} W z)$ & - & 0.838 \\
\hline Arellano-Bond test for $A R(2)(\operatorname{Pr} W z)$ & - & 0.391 \\
\hline Hansen test of overid restrictions & - & 0.103 \\
\hline
\end{tabular}

\section{Discussion and Conclusion}

\section{Discussion}

As the study was conducted in order to investigate and explore the impact of renewable energy consumption, information and communication technologies and E-governance on $\mathrm{CO} 2$ emission on the making of smart cities in Asia in presence of three control variables i.e. population growth and GDP and amount of $\mathrm{CO}_{2}$ Some hypotheses were generated for this purpose, the first hypothesis was that the use of renewable energy plays a significant role in making the smart cities in Asia. Our results proves this hypothesis and are in accordance with the (Karnouskos \& De Holanda, 2009; Pieroni, Scarpato, Di Nunzio, Fallucchi, \& Raso, 2018; Rehmani, Reisslein, Rachedi, Erol-Kantarci, \& Radenkovic, 2018). These studies highly suggest that the use of renewable resources increases the chances of making smart cities. Our second hypothesis was that the use of information and communication technologies in the countries have significant role in the making of the smart cities. Our results are in accordance with the (Battarra, Gargiulo, Pappalardo, Boiano, \& Oliva, 2016; Khatoun \& Zeadally, 2016) that also suggests that the use of information and technology in the country influences the formation of smart cities. Our third hypothesis was that the E-governance on CO2 Emission have significant impact on the formation of the smart cities. Our results showed association of E-governance on $\mathrm{CO} 2$ Emission and formation of smart cities which is in accordance with the other studies by (Ibrahim, Al-Nasrawi, El-Zaart, \& Adams, 2015; Kar, Mustafa, Gupta, Ilavarasan, \& Dwivedi, 2017).

Renewable Energy Consumption plays a vital role on the cost-effective energy generation. This not only decreases in the pollution of the country, global warming but also generate energy for the country. The availability of the energy that is easily available and cost effective have increase chances in the formation of the smart cities. Information and technologies play a huge role in the communication and software's that better works and saves time of the individuals. This effective and efficient work help in the progress of the country thereby generating more smart cities. E-Governance on $\mathrm{CO}_{2}$ emission reduces the emission of the $\mathrm{CO} 2$ by the industries and other sources. If government, make polices and effectively communicate it to the people in the country then there will be more chances in generating smart cities in the Asian countries. 


\section{Conclusion}

Our study was conducted in the data collected from the fifteen Asian countries to assess the role of renewable energy consumption, information and communication technologies and E-governance on Co2 Emission with the formation of the smart cities in the Asia. Different tools were used to analyze the data including LLC, diagnostic checks, correlation matrix and PCSE and sys-GMM estimation test. The results of our study conclude that all the dependent variables have positive influence on the making the smart cities in Asia. Also, GDP have no impact on generating the smart cities whereas, population growth was significantly related to the generation of smart city. Overall, the effect of all the three dependent variables was $59.3 \%$ on the formation of the smart cities.

\section{Limitation and implication}

This study has some implications as well as some limitations. This study has provided with the literature about the impact of the three variables renewable energy consumption, information and communication technologies and E-governance on $\mathrm{CO} 2$ Emission on the formation of smart cities this can be considered as theoretical implication. The practical implication of the study is that the developing countries of Asia who have been struggling with renewable energy consumption, information and communication technologies and E-governance on $\mathrm{CO} 2$ emission should pay more heed to resolving them as this will not only make smart cities but also bring prosperity in the country. This study has also provided assistance and guidance to the policy making departments of government to make such policies and regulations that increase the implementation of these variables to enhance the formation of smart cities in these countries.

The limitation of this study includes the sample size is small and is only limited to fifteen countries of the Asia. A larger prospective study including larger sample size and more countries from different continents of the world should be included. Also, more efficient models for analysis can be used like fixed and random effect modeling.

\section{References}

Adapa, S. (2018). Indian smart cities and cleaner production initiatives-Integrated framework and recommendations. Journal of cleaner production, 172, 3351-3366. https://doi.org/10.1016/j.jclepro.2017.11.250

Agbali, M., Trillo, C., Ibrahim, I. A., Arayici, Y., \& Fernando, T. (2019). Are Smart Innovation Ecosystems Really Seeking to Meet Citizens' Needs? Insights from the Stakeholders' Vision on Smart City Strategy Implementation. Smart Cities, 2(2), 307-327. https:// doi.org/10.3390/smartcities2020019

Alonso-Gonzalez, A., Chacon, L. A. P., \& Peris-Ortiz, M. (2018). Sustainable Social Innovations in Smart Cities: Exploratory Analysis of the Current Global Situation Applicable to Colombia Strategies and Best Practices in Social Innovation (pp. 65-87): Springer. https:// doi.org/10.1007/978-3-319-89857-5_5

Andrés, J. P. (2019). Modern Cities Need a Vision to Shape Their Future City Policies and the European Urban Agenda (pp. 21-65): Springer.

Balogun, A.-L., Marks, D., Sharma, R., Shekhar, H., Balmes, C., Maheng, D., . . Salehi, P. (2019). Assessing the potentials of digitalization as a tool for climate change adaptation and sustainable development in urban centres. Sustainable Cities and Society, 101888. https://doi.org/10.1016/j.scs.2019.101888

Battarra, R., Gargiulo, C., Pappalardo, G., Boiano, D., \& Oliva, J. S. (2016). Planning in the era of information and communication technologies. Discussing the "label: Smart" in South-European cities with environmental and socio-economic challenges. Cities, 59, 1-7. https://doi.org/10.1016/j.cities.2016.05.007

Bhatt, J. G., \& Jani, O. K. (2019). Smart Development of Ahmedabad-Gandhinagar Twin City Metropolitan Region, Gujarat, India Smart Metropolitan Regional Development (pp. 313-356): Springer.

Efthymiopoulos, M.-P. (2016). Cyber-security in smart cities: the case of Dubai. Journal of Innovation and Entrepreneurship, 5(1), 11. https://doi.org/10.1186/s13731-016-0036-x

Gassmann, O., Böhm, J., \& Palmié, M. (2019). Smart Cities: Introducing Digital Innovation to Cities: Emerald Publishing Limited. 
https://doi.org/10.1108/9781787696136

Gupta, P., Chauhan, S., \& Jaiswal, M. (2019). Classification of smart city research-a descriptive literature review and future research agenda. Information Systems Frontiers, 1-25. https://doi.org/10.1007/s10796-019-09911-3

Haseeb, M., Wattanapongphasuk, S., \& Jermsittiparsert, K. (2019). Financial Development, Market Freedom, Political Stability, Economic Growth and CO2 Emissions: An Unexplored Nexus in ASEAN Countries. Contemporary Economics, 13(3), 363-374. https:// doi.org/10.5709/ce.1897-9254.319

Hayat, P. (2016). Smart Cities: a global perspective. India Quarterly, 72(2), 177-191. https://doi.org/10.1177/0974928416637930

Hussain, H.I., Kamarudin, F., Thaker, H.M.T. \& Salem, M.A. (2019) Artificial Neural Network to Model Managerial Timing Decision: Non-Linear Evidence of Deviation from Target Leverage, International Journal of Computational Intelligence Systems, 12 (2), 1282-1294.

Ibrahim, M., Al-Nasrawi, S., El-Zaart, A., \& Adams, C. (2015). Challenges facing e-government and smart sustainable city: An Arab region perspective. Paper presented at the 15th European Conference on e-Government, ECEG.

Kar, A. K., Mustafa, S. Z., Gupta, M. P., Ilavarasan, P. V., \& Dwivedi, Y. K. (2017). Understanding Smart Cities: Inputs for Research and Practice Advances in Smart Cities (pp. 1-7): Chapman and Hall/CRC. https://doi.org/10.1201/9781315156040-1

Karnouskos, S., \& De Holanda, T. N. (2009). Simulation of a smart grid city with software agents. Paper presented at the 2009 Third UKSim European Symposium on Computer Modeling and Simulation. https://doi.org/10.1109/EMS.2009.53

Khatavkar, N., Naik, A., \& Kadam, B. (2017). Energy efficient street light controller for smart cities. Paper presented at the 2017 International conference on Microelectronic Devices, Circuits and Systems (ICMDCS). https://doi.org/10.1109/icmdcs.2017.8211714

Khatoun, R., \& Zeadally, S. (2016). Smart cities: Concepts, architectures, research opportunities. Commun. Acm, 59(8), 46-57. https:// doi.org/10.1145/2858789

Kim, K.-G. (2018). Implementation of Climate Smart City Planning: Global Climate Smart City Platform Solution Low-Carbon Smart Cities (pp. 285-323): Springer. https://doi.org/10.1007/978-3-319-59618-1_7

Kim, K.-G. (2019). Development of an integrated smart water grid model as a portfolio of climate smart cities. Journal of Smart Cities, $3(1), 23-34$.

Kumar, A. (2017). Can the Smart City Allure Meet the Challenges of Indian Urbanization? Sustainable Smart Cities in India (pp. 17-39): Springer. https://doi.org/10.1007/978-3-319-47145-7_2

Kumar, T. V. (2017). E-Democracy for Smart Cities: Conclusion and Path Ahead E-Democracy for Smart Cities (pp. 523-551): Springer. https://doi.org/10.1007/978-981-10-4035-1_18

Kumar, T. V. (2020). International Collaborative Research: "Smart Environment for Smart Cities" and Conclusions of Cities Case Studies Smart Environment for Smart Cities (pp. 491-530): Springer. https://doi.org/10.1007/978-981-13-6822-6_13

Levin, A., Lin, C.-F., \& Chu, C.-S. J. (2002). Unit root tests in panel data: asymptotic and finite-sample properties. Journal of econometrics, 108(1), 1-24. https://doi.org/10.1016/S0304-4076(01)00098-7

Mboup, G., \& Oyelaran-Oyeyinka, B. (2019). Relevance of Smart Economy in Smart Cities in Africa Smart Economy in Smart African Cities (pp. 1-49): Springer. https://doi.org/10.1007/978-981-13-3471-9_1

Menkhoff, T., Kan, S. N., Evers, H.-D., \& Chay, Y. W. (2017). Living in Smart Cities: Innovation and Sustainability: World Scientific. https://doi.org/10.1142/10785

Pieroni, A., Scarpato, N., Di Nunzio, L., Fallucchi, F., \& Raso, M. (2018). Smarter city: smart energy grid based on blockchain technology. Int. J. Adv. Sci. Eng. Inf. Technol, 8(1), 298-306. http://dx.doi.org/10.18517/ijaseit.8.1.4954

Pozdniakova, A. M. (2017). Smart sustainable cities: the concept and approaches to measurement. Acta Innovations (22), 5-19.

Praharaj, S., \& Han, H. (2019). Cutting through the clutter of smart city definitions: A reading into the smart city perceptions in India. City, Culture and Society. https://doi.org/10.1016/j.ccs.2019.05.005

Rehmani, M. H., Reisslein, M., Rachedi, A., Erol-Kantarci, M., \& Radenkovic, M. (2018). Integrating renewable energy resources into the smart grid: Recent developments in information and communication technologies. IEEE Transactions on Industrial Informatics, 14(7), 2814-2825. https://doi.org/10.1109/TII.2018.2819169 
Ryser, J. (2016). Smart Cities or Smart About Cities. Paper presented at the REAL CORP 2016-SMART ME UP! How to become and how to stay a Smart City, and does this improve quality of life? Proceedings of 21 st International Conference on Urban Planning, Regional Development and Information Society.

Sánchez-Corcuera, R., Nuñez-Marcos, A., Sesma-Solance, J., Bilbao-Jayo, A., Mulero, R., Zulaika, U., . . Almeida, A. (2019). Smart cities survey: Technologies, application domains and challenges for the cities of the future. International Journal of Distributed Sensor Networks, 15(6), 1550147719853984. https://doi.org/10.1177\%2F1550147719853984

Sarma, U., Karnitis, G., Zuters, J., Karnitis, E. (2019). District heating networks: enhancement of the efficiency, Insights into Regional Development, 1(3), 200-213. https://doi.org/10.9770/ird.2019.1.3(2)

Sharifi, A. (2019). A typology of smart city assessment tools and indicator sets. Sustainable Cities and Society, 101936. https://doi. org/10.1016/j.scs.2019.101936

Smith, R. M., Pathak, P. A., \& Agrawal, G. (2019). India's “smart” cities mission: A preliminary examination into India's newest urban development policy. Journal of Urban Affairs, 41(4), 518-534. https://doi.org/10.1080/07352166.2018.1468221

Sureshchandra, S. M., Bhavsar, J. J., \& Pitroda, J. R. (2016). Review on Identification of Success Factors for Designing of Smart Cities. International Journal of Science Technology \& Engineering, 2, 125-133.

Tomor, Z., Meijer, A., Michels, A., \& Geertman, S. (2019). Smart Governance For Sustainable Cities: Findings from a Systematic Literature Review. Journal of Urban Technology, 26(4), 3-27. https://doi.org/10.1080/10630732.2019.1651178

Vlasov, A.I., Grigoriev, P.V., Krivoshein, A.I., Shakhnov, V.A. Filin, S.S., Migalin, V.S. (2019). Smart management of technologies: predictive maintenance of industrial equipment using wireless sensor networks, Entrepreneurship and Sustainability Issues, 6(2), 489-502. http://doi.org/10.9770/jesi.2018.6.2(2)

Vlasov, A.I., Shakhnov, V.A., Filin, S.S., Krivoshein, A.I. (2019). Sustainable energy systems in the digital economy: concept of smart machines. Entrepreneurship and Sustainability Issues, 6(4), 1975-1986. http://doi.org/10.9770/jesi.2019.6.4(30)

Yigitcanlar,T.(2016). Technology and the city: Systems, applications and implications: Routledge.https://doi.org/10.4324/9781315739090

Yigitcanlar, T., Kamruzzaman, M., Buys, L., Ioppolo, G., Sabatini-Marques, J., da Costa, E. M., \& Yun, J. J. (2018). Understanding 'smart cities': Intertwining development drivers with desired outcomes in a multidimensional framework. Cities, 81, 145-160. https:// doi.org/10.1016/j.cities.2018.04.003

Witthaya MEKHUM is an Associate Professor and the Vice President for Planning and Quality Assurance of Suan Sunandha Rajabhat University, Thailand. His research areas are Industrial Technology, Security Management, and Material Management.

ORCID ID: orcid.org/0000-0002-9667-3730

This work is licensed under the Creative Commons Attribution International License (CC BY). http://creativecommons.org/licenses/by/4.0/ 